J. AMER. SOC. HorT. SCI. 117(2):351-356. 1992.

\title{
Substantial Errors in Estimates of Sap Flow Using the Heat Balance Technique on Woody Stems under Field Conditions
}

\author{
Kenneth A. Shackel, R. Scott Johnson, and Charles K. Medawar \\ Department of Pomology, University of California, Davis, CA 95616-8683
}

Claude J. Phene

U.S. Department of Agriculture, Agricultural Research Service, Water Management Research

Laboratory, 2021 South Peach Avenue, Fresno, CA 93727

Additional index words. lysimeter, peach, Prunus persica, transpiration

Abstract. The heat balance method was used to estimate transpirational sap flow through 60- to 75-mm-diameter stems (trunks) of 3-year-old peach [Prunus persica (L.) Batsch. cv. O'Henry] trees under field conditions. On rare occasions, heat balance estimates agreed well with independent lysimetric measurements, but on most occasions, heat balance estimates of sap flow were unrealistic in both direction and magnitude. In some cases, the errors in sap flow approached two orders of magnitude and were always the result of a calculation involving division by a very small and sometimes negative temperature differential between the stem surface temperature above and below the gauge heater. The occurrence of negative temperature differentials under positive transpiration conditions may be inconsistent with a fundamental assumption in the heat balance model, namely that temperature differentials are solely a consequence of the dissipation of energy supplied to the gauge heater. In the absence of heating power applied to the gauge, temperature differentials exceeding - $1 \mathrm{C}$ were correlated with the rate of change in stem temperature, indicating that ambient conditions themselves can impose a bias in gauge signals and, hence, influence gauge accuracy. Our results suggest that the effect of ambient conditions on gauge signals should be critically evaluated before considering heat balance estimates of sap flow as reliable under any given conditions.

Some recent papers have reported accurate in situ estimates of sap flow (transpiration) through both herbaceous (Ham and Heilman, 1990) and woody (Steinberg et al., 1990b) plant stems using the heat balance technique. The most recent development of this technique has been based on a constant heating gauge described by Sakuratani $(1981,1984)$ and further modified by Baker and Van Bavel (1987). In most of these reports, the theory of operation for the gauge itself has been described, but only in terms of the numerical calculations needed to convert gauge signals (largely thermojunction-measured temperature differentials) into sap mass flow. Some of the assumptions underlying the heat balance technique have been evaluated with a finite element model (Baker and Nieber, 1989) that showed that gauge accuracy may be influenced by factors such as stem vascular anatomy, with potentially greater accuracy in dicots than in monocots. The same analysis indicated that overall gauge accuracy could be relatively good, however, depsite the presence of systematic errors in estimates of some of the heat balance components. In view of the accuracy reported in some studies (Steinberg et al., 1989) and reproducibility reported in others (Heilman et al., 1989), it is reasonable to assume that heat balance estimates of sap flow are reliable and that errors, if present, are of minor significance. One class of errors that has not been considered, however, are those associated with the measurement of the temperature differential on the stem surface from below to above the gauge heater. Baker and Nieber (1989) recognized that this temperature differential is critical in the calculation of sap flow, but also that errors in its determination could not be formally considered within the theoretical model of gauge function. In effect, the heat balance theory is limited to considering only temperature differentials that result from

Received for publication 15 Apr. 1991. Accepted for publication 12 Nov. 1991. The cost of publishing this paper was defrayed in part by the payment of page charges. Under postal regulations, this paper therefore must be hereby marked advertisement solely to indicate this fact. heat energy applied to the stem itself. Since large and diurnally fluctuating differences between soil and air temperature are commonplace under many field conditions, and since the plant represents a bridge between these two thermal regimes, it is reasonable to examine to what extent such environmental temperature differentials lead to differentials within the plant stem, and the impact of these on the measurement of sap flow. This study documents that such differentials do occur and may be potentially large enough to cause substantial errors in the measurement of sap flow by the heat balance technique.

\section{Materials and Methods}

The gauge used in this study was a commercially available SGB50 (Dynamax, Houston), and gauge signals were recorded using a CR10 datalogger (Campbell Scientific, Logan, Utah) that was programmed to measure at 15 -sec intervals and store average values over 10 -min periods. The theory of operation and measurements required to determine transpirational sap flow using this heat balance gauge have been described (Baker and Van Bavel, 1987; Ham and Heilman, 1990). Briefly, three categories of measurements are required: 1) the power (in watts) applied to the gauge heater, 2) the temperature gradients associated with passive vertical heat conduction along the stem and with radial heat conduction through the gauge insulation layer, and 3) the overall difference in stem temperature from below the heater to above the heater (AT). The temperature gradient (" $\mathrm{C} / \mathrm{m}$ ) associated with vertical heat conduction is measured at the stem surface and is converted to power by multiplying by the specific thermal conductivity of wood and by the appropriate stem cross-sectional area. In this study a value of $0.42 \mathrm{~W} / \mathrm{m}$ per C (Steinberg et al., 1990b) was used as the thermal con-

Abbreviation: ET, evapotranspiration. 
ductivity of wood, although, as found by Steinberg et al. (1990a), the specific value used for this factor had a relatively minor influence on the calculated sap flow rates. A radial temperature gradient, which is measured across a portion of the gauge insulation layer, is converted to power lost radially through the insulation by assuming that 1) all power lost to radial conduction is directly proportional to this temperature gradient, and 2) that, under zero transpiration conditions, all of the power applied to the heater is partitioned between vertical (known) and radial conduction (obtained by difference). The apparent radial conductivity, also called sheath conductance (Baker and Van Bavel, 1987), is simply the power remaining after subtracting vertical power loss from heater power under zero transpiration conditions and dividing this by the measured value of the radial temperature gradient. The conductivity obtained in this way has been referred to as a "zero set" (Baker and Van Bavel, 1987), but it is rather an empirical coefficient that calibrates, with a single point, the relation of radial power loss to a measured radial temperature gradient. Based on lysimeter data (e.g., Fig. 1), we assumed that transpiration dropped to 0 between 2:00 and 6:00 (local time), and, as in Steinberg et al. (1989), the minimum apparent radial conductivity during this time was used for the following 24-h period. Finally, the transpirational sap mass flow rate was obtained at any time during the day by subtracting the calculated vertical and radial power losses from the total power applied to the gauge heater and dividing the result by the product of the stem AT, measured on the stem surface, and the heat capacity of water.

The gauge was installed as recommended by the manufacturer, using a PVC weather shield covered with aluminum foil and supported by foam extension rings (total length of stem insulated $\approx 40 \mathrm{~cm}$ ). A high-dielectric waterproofing grease (Dow Corning 4; Dow Corning, Midland, Mich.) was applied to the gauge thermocouples to prevent wetting and improve thermal contact with the stem (main trunk), in addition to installing the gauge tightly around the stem at midday. For the young trees used in this study, stem diameters ranged from 60 to $75 \mathrm{~mm}$, and there was no dead or loose bark that required removal or sanding to ensure good stem-to-thermocouple contact (Steinberg et al., 1990a). When power was applied to the gauge, a regulated voltage source was adjusted to supply $2.2 \mathrm{~W}$ to the gauge heater, which was higher than the $1.4 \mathrm{~W}$ suggested by the manufacturer. The higher power was based on preliminary tests designed to increase stem AT as far as possible without causing excessively high stem temperatures at night. On some occasions, 5 to $7 \mathrm{~cm}$ of additional insulation covered by aluminum foil was applied around the gauge, to $25 \mathrm{~cm}$ on the stem and scaffold branches above the gauge and extending to the soil surface below the gauge. An additional thermocouple was placed in the center of the gauge between the stem surface and the gauge heater for measurement of heated stem temperature (Steinberg et al., 1989). The plants used were 3-year-old peach trees planted in north-south-oriented rows at a uniform 1.8 (within) $\times 4.9-\mathrm{m}$ (between row) spacing, including the lysimeter trees, throughout a 1.1-ha experimental plot in Parlier, Calif. Two trees in the center of this plot were located in a $4 \times 2 \times 2-\mathrm{m}$ weighing lysimeter, accurate to $\pm 0.2 \mathrm{~kg}$ (Phene et al., 1991), which was automated both to record water loss and irrigate by replacing lysimeter tree evapotranspiration (ET) every $12 \mathrm{~mm}$. All trees in this study were well irrigated and had been pruned to a single $50 \pm 5$-cm-long trunk with two scaffold branches forming a "V" perpendicular to the tree row. When heat balance measurements were made on a tree in the lysimeter, the lysimeter soil surface was covered with a plastic sheet, so that all measured water loss could be attributed to plant water loss. The 10-min average gauge signals were used to compute sap flow rates that were further averaged over 1-h periods to match the measurement period of the lysimeter. The two lysimeter trees were essentially identical in overall size and stem diameter throughout the period of this study.

Environmental data (Table 1; air and soil temperatures, evaporative demand, etc.) were obtained from a nearby weather station (CIMIS station \#39, Parlier).

\section{Results and Discussion}

For the 36 individual days (1 May-17 Oct. 1990) during which power was applied to the gauge heater, reasonable agreement between lysimeter and heat balance measurements of hourly transpiration rates were only found on two occasions (Fig. 1). In these cases, as reported by Steinberg et al. (1990b), there was no apparent time lag between the two methods, indicating that tree capacitance effects were minimal. The agreement was also good under both low (11 Apr.) and high (13 June) flow conditions. The lower flow rates on $11 \mathrm{Apr}$. were the result of the tree being smaller, as measured by overall canopy dimensions $(\mathrm{H} \times \mathrm{W} \times \mathrm{L}=2.65 \times 1.05 \times 2.15 \mathrm{~m})$, together with lower evaporative demands (Table 1), as compared to the conditions on 13 June $(\mathrm{H} \times \mathrm{W} \times \mathrm{L}=3.05 \times 1.35 \times 2.2 \mathrm{~m})$. The gauge signals found under these conditions (Fig. 2) were consistent with the theory of gauge function and also similar to those found in other studies (Ham and Heilman, 1990). The transient spike in stem $\Delta \mathrm{T}$ and vertical heat conduction that occurred in the morning hours (Fig. 2, 8:00) probably reflected the slow ascent of sap that had been heated during the night hours (as suggested by Ham and Heilman, 1990), but this event caused no apparent transient in the calculated transpiration rates (Fig. 1). These results indicated that the gauge and its measurement system were operated properly, and appeared to justify the assumptions underlying the calculation of transpirational sap flow using the heat balance technique.

On most occasions, however, heat balance estimates of transpirational sap flow differed widely from those measured by the lysimeter, in some cases showing excessively high flows in the morning hours, but in other cases showing discrepancies throughout the day that approached two orders of magnitude (Fig. 3). These discrepancies had no apparent relation to environmental conditions; for instance, most of the environmental conditions for the period shown in Fig. 3 were similar to those of 13 June in Fig. 1 (Table 1). The diurnal patterns in all of the gauge signals on these occasions were similar to those shown

Table 1. Environmental conditions during the days of data collection in 1990 that are depicted in Figs. 1-3.

\begin{tabular}{|c|c|c|c|c|c|c|c|c|}
\hline \multirow[b]{2}{*}{ Date } & \multirow{2}{*}{$\begin{array}{c}\text { Solar } \\
\text { radiation } \\
\left(\mathrm{W} \cdot \mathrm{m}^{-2}\right)\end{array}$} & \multicolumn{3}{|c|}{ Air temp $\left({ }^{\circ} \mathrm{C}\right)$} & \multicolumn{2}{|c|}{$\mathrm{RH}^{\mathrm{z}}(\%)$} & \multirow{2}{*}{$\begin{array}{l}\text { Windy } \\
\left(\mathrm{m} \cdot \mathrm{s}^{-1}\right)\end{array}$} & \multirow{2}{*}{$\begin{array}{l}\mathrm{ET}_{0}{ }^{\mathrm{x}} \\
(\mathrm{mm})\end{array}$} \\
\hline & & Min & Max & Mean & Min & $\operatorname{Max}$ & & \\
\hline 11 Apr. & 300 & 8 & 29 & 19.7 & 19 & 88 & 2.5 & 5.70 \\
\hline 2 June & 362 & 10 & 29 & 19.8 & 29 & 95 & 1.4 & 6.06 \\
\hline 3 June & 361 & 13 & 31 & 22.3 & 31 & 90 & 2.3 & 6.86 \\
\hline 4 June & 361 & 14 & 31 & 22.2 & 26 & 93 & 2.1 & 6.75 \\
\hline 13 June & 362 & 11 & 26 & 19.3 & 36 & 86 & 2.8 & 6.77 \\
\hline
\end{tabular}

${ }^{\mathrm{z}}$ Relative humidity.

${ }^{\mathrm{y}}$ Daily mean values.

${ }^{\mathrm{x}}$ Reference crop evapotranspiration. 


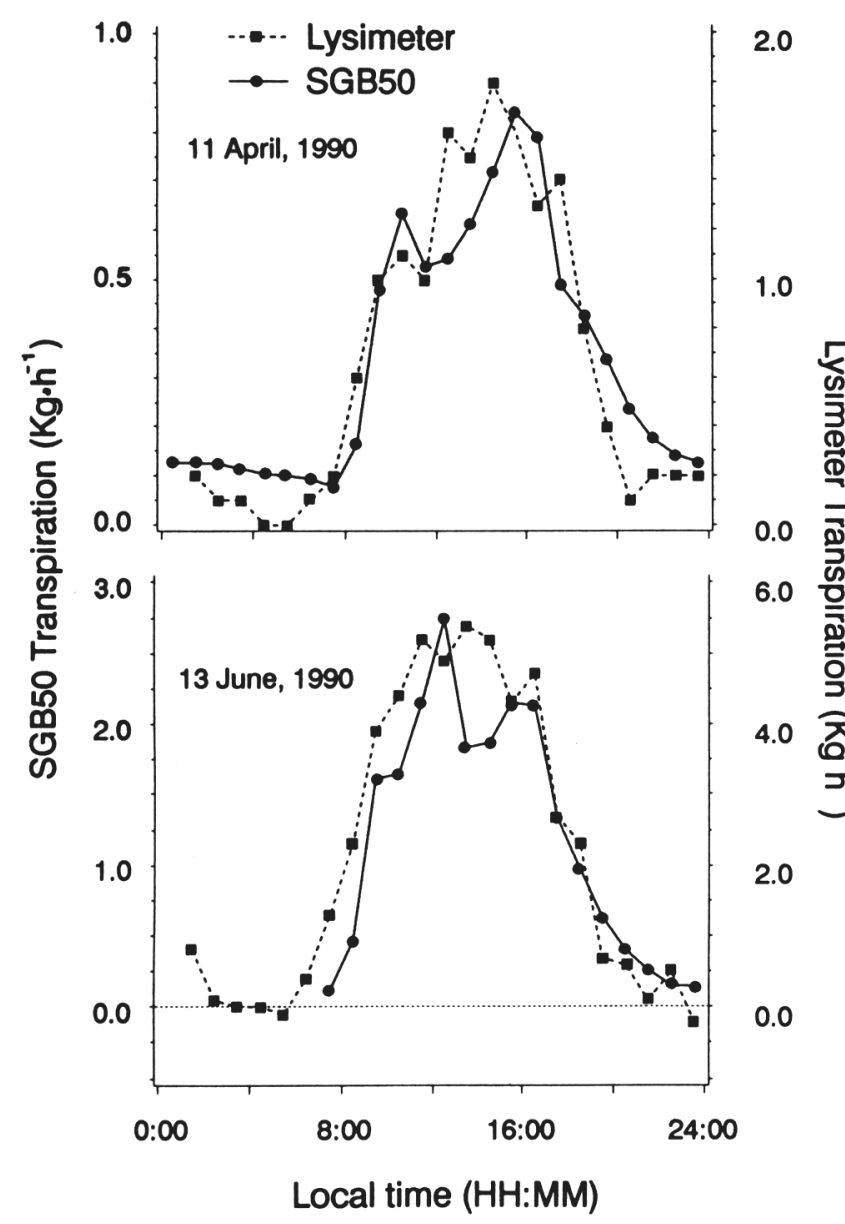

Fig. 1. Comparison of hourly average transpiration rates as determined by a weighing lysimeter (right axis) and by a heat balance gauge (SGB50, left axis) on two dates in 1990. The heat balance data were collected from one of the two trees in the lysimeter, so the scale for lysimeter measurements is one-half the size of the heat balance scale. The stem diameter of the tree used for heat balance measurements was $61 \mathrm{~mm}$ on $11 \mathrm{Apr}$. and $64 \mathrm{~mm}$ on 13 June.

in Fig. 2, and the erroneous sap flow rates were always the result of very small (sometimes negative) values for stem $\Delta \mathrm{T}$ (Fig. 3). As recognized by Ham and Heilman (1990), the stem $\Delta \mathrm{T}$ factor is in the denominator of the expression used to calculate apparent sap flow, and as $\Delta \mathrm{T}$ becomes small, very small changes in $\Delta \mathrm{T}$ will cause very large changes in calculated flow. Since heat energy was clearly being added to the stem during these times, and since it was equally clear that sap flow through the tree must have been positive, the occurrence of a negative $\Delta \mathrm{T}$ indicated that some additional factor, not considered within the theory of gauge function, was affecting stem $\Delta \mathrm{T}$.

To test for environmental influences on stem $\Delta \mathrm{T}$, the gauge was operated under ambient field conditions, without supplying power to the heater. Under these conditions the surface temperature of the stem within the gauge exhibited substantial diurnal variation, typically being intermediate between air and soil temperatures during the night and below both air and soil temperature during the day (Fig. 4). This diurnal pattern in stem temperature was presumably the result of diurnal changes in soil and air temperatures, together with diurnal patterns of tree transpiration. For instance, at night, a gradient existed for heat conduction from the warmer soil to the cooler air (Fig. 4), and, hence, stem temperature
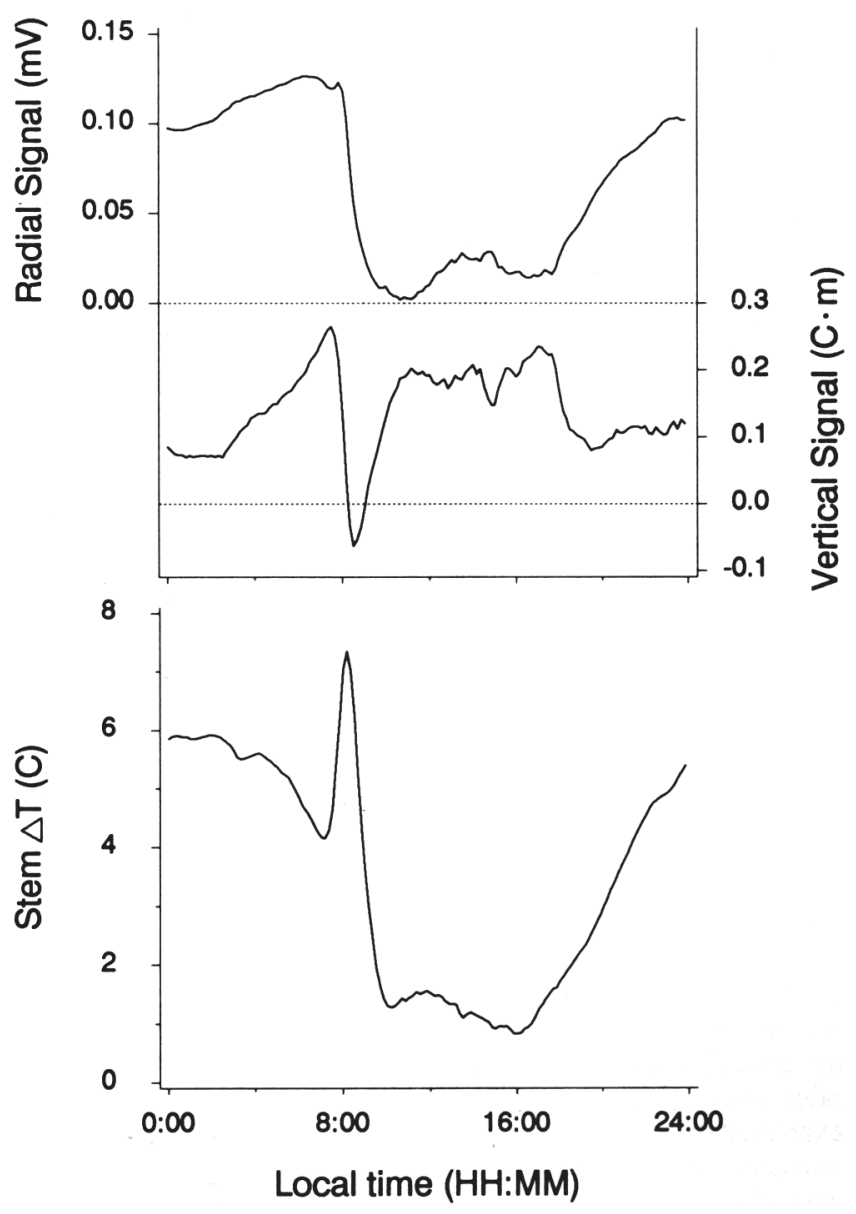

Fig. 2. Ten-minute average signals recorded from the heat balance gauge shown in Fig. 1 on 11 Apr. 1990. The vertical signal, which includes the factor of stem cross-sectional area, must be multiplied by an assumed specific thermal conductivity of wood (in W/m per ${ }^{\circ} \mathrm{C}$ ) to give the power (W) lost to vertical heat conduction.

may be expected to be intermediate between these two. During the day, stem temperature may be largely determined by the temperature of the water pulled by transpiration from the soil at and below $15 \mathrm{~cm}$, which is cooler than the air. Regardless of the source, however, it was clear that ambient conditions substantially influenced stem temperatures on a diurnal basis. Over the course of the season, clear diurnal patterns were exhibited in both stem temperature and stem $\Delta \mathrm{T}$ under nonheated conditions (Fig. 5). Regardless of the quantity of insulation applied to the gauge, in all tests, substantial stem $\Delta \mathrm{T}$ values on the order of $\pm 1 \mathrm{C}$ were exhibited during at least some part of the diurnal cycle. In most cases, $\Delta \mathrm{T}$ values were positive at night and negative during the day, especially midmorning (Fig. 5). The examples shown in Fig. 5 represent the seasonal range of stem temperatures recorded during this study and demonstrate that there was no apparent relation between the value of stem temperature itself and stem $\Delta \mathrm{T}$.

One explanation for the occurrence of stem $\Delta \mathrm{T}$ values in the absence of heat input is that when stem temperature is changing (Fig. 4), temperatures at different positions along the stem do not change at the same rate. If this were the case, then the largest stem $\Delta \mathrm{T}$ values would be expected to occur under conditions of the most rapid changes in stem temperature, and, conversely, the smallest $\Delta \mathrm{T}$ values should occur when stem temperature is relatively stable over time, allowing all positions 


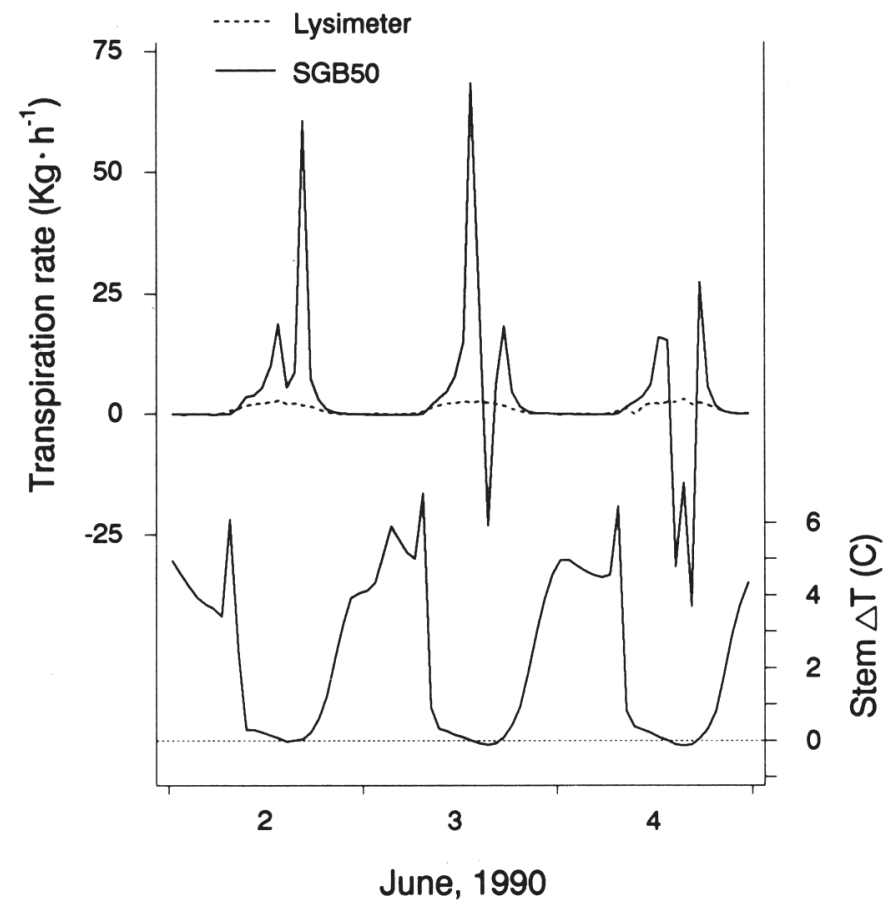

Fig. 3. Comparison of hourly average transpiration rates for lysimeter and heat balance methods as in Fig. 1 and the corresponding hourly average stem $\Delta \mathrm{T}$. Heat balance data were collected from a tree in the ground that had a stem diameter of $63 \mathrm{~mm}$, which was comparable in overall size to the trees in lysimeters. Lysimeter values are expressed on a per-tree basis (i.e., one-half of the two-tree lysimeter transpiration rate) but with an exposed soil surface; hence, they overestimate (in this case $\approx 20 \%$ ) the transpiration from a single tree by including some soil evaporation. The daily water lost from the lysimeter was 23.3, 25.1, and $25.0 \mathrm{~kg} /$ tree for 2-4 June 1990, respectively. Ticks on the $\mathrm{x}$-axis are at midnight.

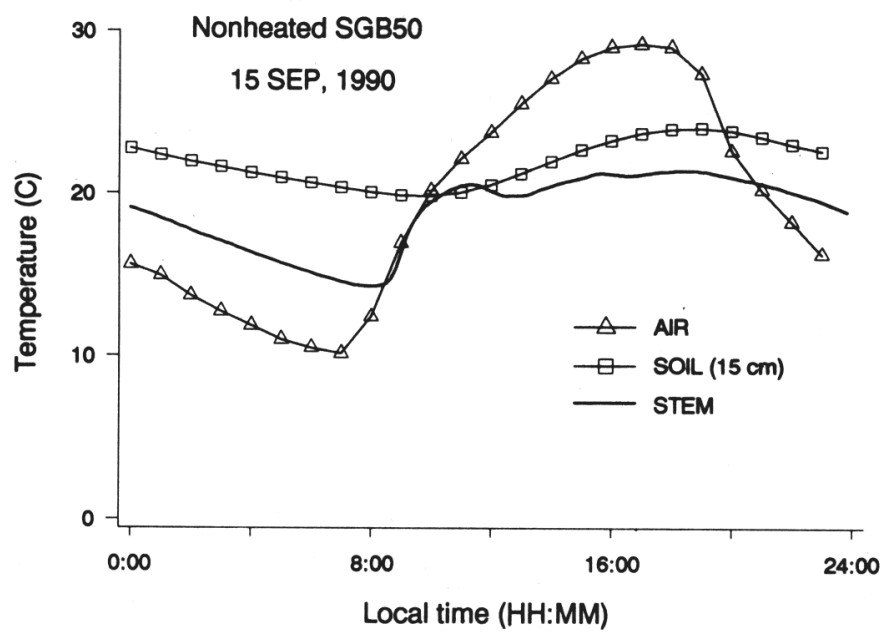

Fig. 4. Diurnal patterns of air temperature, soil temperature at a 15 $\mathrm{cm}$ depth, and the surface temperature of the stem within the gauge on 1.5 Sept. 1990 in the absence of energy applied to the gauge heater. Air and soil temperature values represent hourly averages obtained from a nearby weather station, whereas stem temperatures are 10-min averages. Stem diameter was $69 \mathrm{~mm}$.

along the stem to approach thermal equilibrium. Consistent with this hypothesis, diurnal patterns of stem $\Delta \mathrm{T}$ were generally the
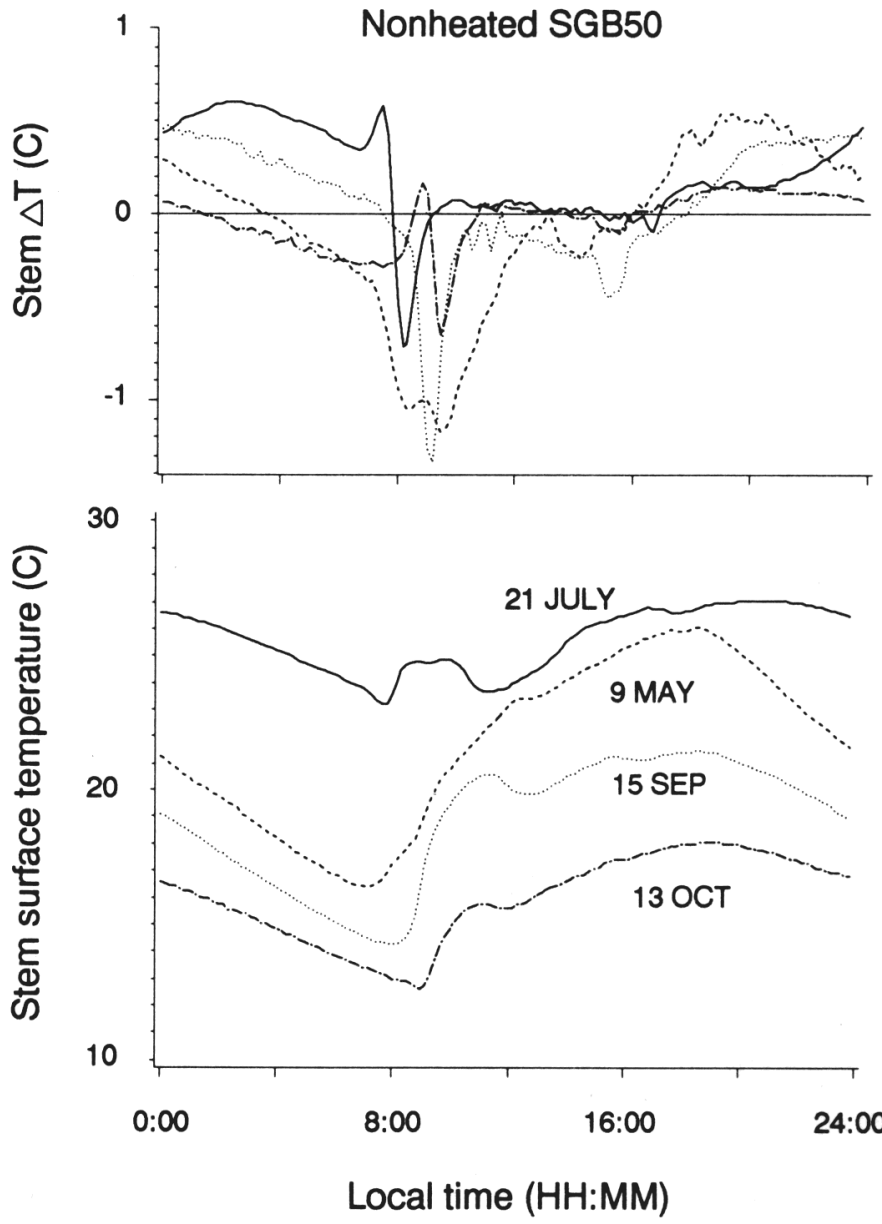

Fig. 5. Diurnal patterns of stem $\Delta \mathrm{T}$ in the absence of energy applied to the gauge heater and the corresponding surface temperatures of the stem within the gauge on four individual days in 1990. Stem diameters ranged from $60 \mathrm{~mm}$ in May to $75 \mathrm{~mm}$ in October.

inverse of diurnal patterns in the rate of change in stem temperature (dT/dt, or the slope of the line describing stem temperature over time as in Figs. 4 and 5), with minimum stem $\Delta \mathrm{T}$ values occurring at the time of maximum $\mathrm{dT} / \mathrm{dt}$, and vice versa (Fig. 6). This qualitative relation was summarized by pooling the data for all of the 34 days when the gauge was not heated during the season (Fig. 7). These pooled data showed that, in addition to a substantial degree of variability, a clearly inverse relation of stem $\Delta \mathrm{T}$ to stem $\mathrm{dT} / \mathrm{dt}$ occurred during most of the diurnal cycle. Stem $\Delta \mathrm{T}$ was largely independent of $\mathrm{dT} / \mathrm{dt}$ around midday, however, suggesting that the change in temperature of different points within the gauge (e.g., the two used to calculate $\Delta \mathrm{T}$ ) was relatively uniform when it occurred during periods of presumably high transpirational flow. Since all of these results were obtained under nonheated gauge conditions, they indicate that the stem $\Delta \mathrm{T}$ measured by the gauge may be influenced by a bias, correlated to the rate of change in stem temperature, as it is influenced by diurnal changes in ambient temperatures. This bias in stem $\Delta \mathrm{T}$ may, in addition, be a function of the level of transpirational water flux through the stem itself.

These results indicate that environmental conditions that cause temperature differences along the stem may violate one of the simplifying assumptions underlying the heat balance technique by imposing a bias, which for this study was on the order of $\pm 1 \mathrm{C}$, on the measurement of stem $\Delta \mathrm{T}$. The magnitude of the 


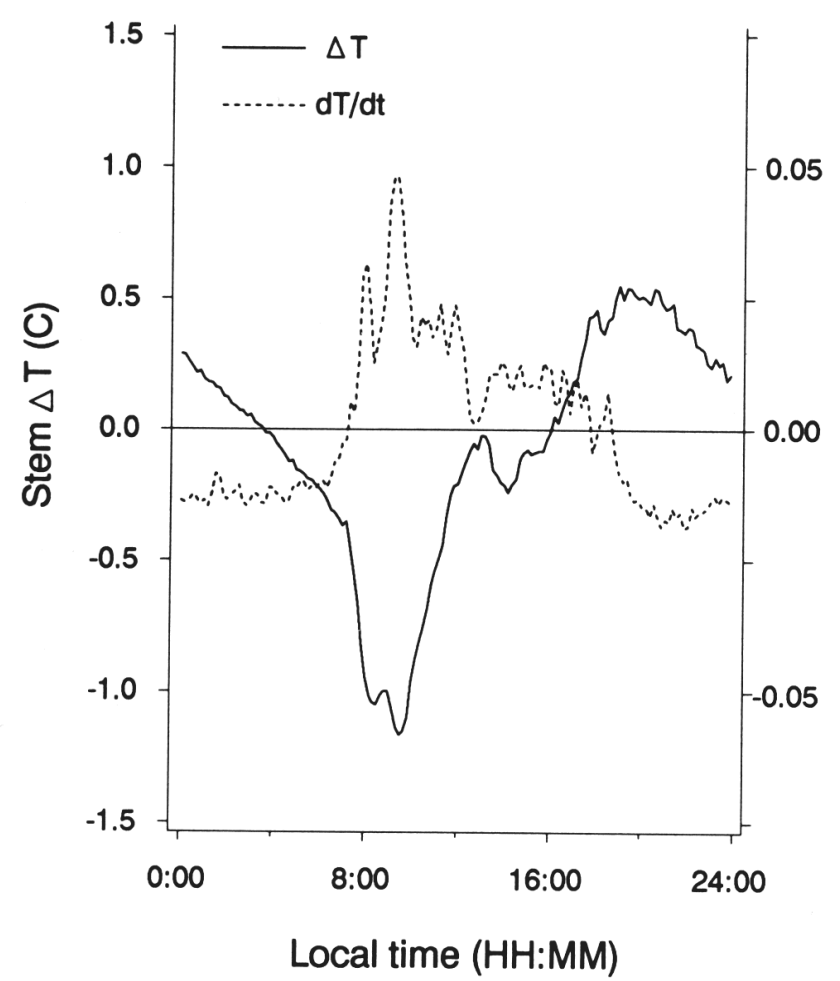

Fig. 6. Diurnal pattern of nonheated stem $\Delta \mathrm{T}$ (as in Fig. 5) and the corresponding pattern in the rate of change in surface temperature of the stem within the gauge (dT/dt) on 9 May 1990.

error caused by this bias will depend primarily on the magnitude of the bias, compared to the magnitude of the true $\Delta \mathrm{T}$, which is needed to calculate flow. For instance, in some studies (Ham and Heilman, 1990), a measured $\Delta \mathrm{T}$ of $1 \mathrm{C}$ was used to calculate flow. If a bias of only $-0.9 \mathrm{C}$ had existed, an overestimate in calculated flow of one order of magnitude $(1000 \%)$ would have resulted. In other studies (Steinberg et al., 1989), a $\Delta \mathrm{T}$ of 4 to $7 \mathrm{C}$ was used, for which the same $-0.9 \mathrm{C}$ bias would have caused a $15 \%$ to $30 \%$ overestimate of flow. The potential for error due to a $\Delta \mathrm{T}$ bias is substantial, but the impact of this error on overall gauge accuracy is impossible to evaluate in general terms, since gauge accuracy depends on several interrelated factors. It is possible, for instance, that accurate gauge estimates of transpiration under some conditions could be the fortuitous result of correlated or compensating errors, as suggested from the theoretical analysis of Baker and Nieber (1989) for errors in the estimates of heat conduction. Interestingly, their analysis indicated that the net result of these errors was a slight underestimate of sap mass flow in dicot stems and a more severe underestimate in monocot stems. Clearly, a negative $\Delta \mathrm{T}$ bias of an appropriate magnitude could compensate for such an underestimate, since a reduced $\Delta \mathrm{T}$ would correspondingly increase the estimate of transpirational flow.

Most studies concerning the accuracy of the heat balance technique have been conducted under greenhouse or controlledenvironment conditions, which may have exhibited less overall temperature variability in the soil and air than found under the conditions of this study. In addition, many studies have reported results using smaller-sized stems and gauges, which would be expected to exhibit a shorter time to reach thermal equilibrium by passive heat conduction than the larger stems and gauges we used. Both of these factors may have resulted in better temper-

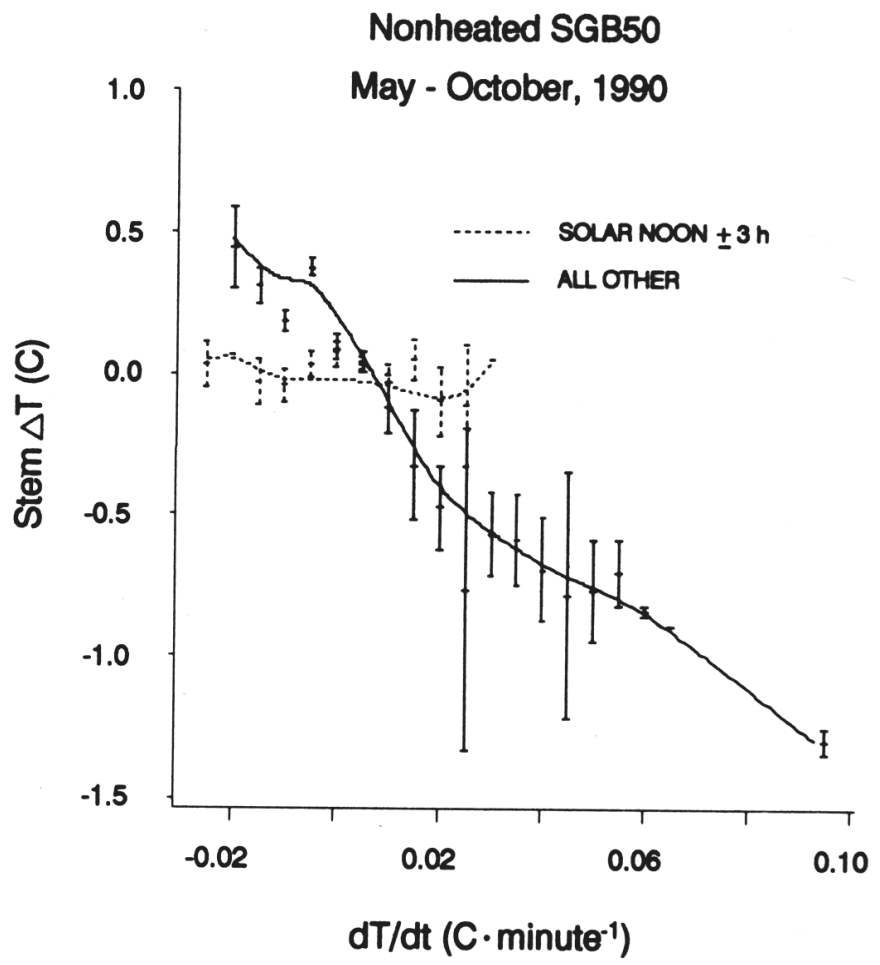

Fig. 7. Relationship of nonheated stem $\Delta \mathrm{T}$ to the rate of change in surface temperature of the stem within the gauge (dT/dt) over 34 individual days in 1990. Vertical lines represent the mean $\pm 1 \mathrm{SD}$ for data points pooled into $0.005 \mathrm{C} / \mathrm{min}$ categories of $\mathrm{dT} / \mathrm{dt}$. Curves are smoothed spline fits through all data points representing high (solar noon $\pm 3 \mathrm{~h}$ ) and low (all other) transpiration conditions. The number of individual points represented is $\approx 4900$.

ature uniformity within the stem than observed by us and may account for the reasonable accuracy reported earlier (Steinberg et al., 1989). However, field studies using large gauges have also reported accurate estimates (Steinberg et al., 1990b), although no data were presented concerning the magnitude of gauge signals exhibited under nonheated, ambient conditions. Since a bias in $\Delta \mathrm{T}$ could, in theory, compensate for other errors in the heat balance system, our results, together with those of Baker and Nieber (1989), suggest that a simple comparison to independently measured transpiration does not by itself verify the correctness of the heat balance approach for the measurement of sap flow. We suggest that the effect of ambient conditions on gauge signals, especially gauge $\Delta \mathrm{T}$, should be evaluated before considering heat balance estimates of sap flow as reliable under any given conditions. If environmental effects, such as those reported here, are present, then simple mathematical correction of the gauge signals may not be possible, in part because of day-to-day variability (Fig. 5), but also because the pattern of change in stem temperature may not be the same under heated and nonheated conditions. To use the heat balance technique under a range of field conditions, it may be necessary to modify gauge design further or to control ambient temperatures in the vicinity of the heat balance gauge itself.

The accuracy of the heat balance method for measurement of transpirational sap flow using commercially available gauges may strongly depend on the environmental conditions under which the gauges are operated. The most substantial effect found in this study was that of ambient and stem temperature changes on stem $\Delta \mathrm{T}$. Our results suggest that the effect of ambient 
conditions on gauge signals, especially $\Delta \mathrm{T}$, should be evaluated before accepting heat balance estimates of sap flow as reliable under any given environmental conditions.

\section{Literature Cited}

Baker, J.M. and J.L. Nieber. 1989. An analysis of the steady-state heat balance method for measuring sap flow in plants. Agr. Forest Meterol. 48:93-109.

Baker, J.M. and C.H.M. Van Bavel. 1987. Measurement of mass flow of water in the stems of herbaceous plants. Plant Cell Environ. 10:777-782.

Ham, J.M. and J.L. Heilman. 1990. Dynamics of a heat balance stem flow gauge during high flow. Agron. J. 82:147-152.

Heilman, J.L., C.L. Brittin, and J.M. Zajicek. 1989. Water use by shrubs as affected by energy exchange with building walls. Agr. Forest Meterol. 48:345-357.
Phene, C.J., G.J. Hoffman, T.A. Howell, D.A. Clark, R.M. Mead, R.S. Johnson, and L.E. Williams. 1991. Automated lysimeter for irrigation and drainage control. Proc. Intl. Conf. Lysimetry, Amer. Soc. of Civil Eng. Honolulu, 27 July 1991.

Sakuratani, T. 1981. A heat balance method for measuring water flux in the stem of intact plants. J. Agr. Meterol. 37:9-17.

Sakuratani, T. 1984. Improvement of the probe for measuring water flow rate in intact plants with the stem balance method. J. Agr. Met. 40:273-277.

Steinberg, S.L., C.H.M. van Bavel, and M.J. McFarland. 1989. A gauge to measure mass flow rate of sap in stems and trunks of woody plants. J. Amer. Soc. Hort. Sci. 114:466-472.

Steinberg, S.L., C.H.M. van Bavel, and M.J. McFarland. 1990a. Improved sap flow gauge for woody and herbaceous plants. Agron. J. 82:851-854.

Steinberg, S.L., M.J. McFarland, and J.W. Worthington. 1990b. Comparison of trunk and branch sap flow with canopy transpiration in pecan. J. Expt. Bot. 41:653-659. 